\title{
A comparison of sympathoadrenal activity and cardiac performance at rest and during exercise in patients with ventricular demand or atrial synchronous pacing
}

\author{
S KENNETH PEHRSSON, PAUL HJEMDAHL, ROLF NORDLANDER, \\ HANS ÅSTRÖM \\ From the Division of Cardiology, Departments of Medicine and Clinical Physiology, Thoracic Clinics, \\ Karolinska Hospital and Department of Pharmacology, Karolinska Institute, Stockholm, Sweden
}

SUMMARY Cardiac sympathetic function was assessed by measuring the coronary sinus overflow $\overrightarrow{c \rho}$ of noradrenaline and dopamine at rest and during supine exercise in eight patients with high degree atrioventricular block treated with dual chamber pacemakers (DDD). Patients exercised (30-60. W) during both ventricular inhibited (VVI) and atrial synchronous (VAT) pacing. During exercise cardiac output increased less markedly in the VVI mode than in the VAT mode. The cardiac ${ }^{\mathbb{D}}$ output response was entirely stroke volume dependent in the VVI mode and mainly heart rate $\overrightarrow{0}$ dependent in the VAT mode. Coronary sinus noradrenaline concentrations were higher in the VVID mode at rest and during exercise. Noradrenaline overflow from the heart was enhanced during VVID pacing and increased from about $100 \mathrm{pmol} / \mathrm{min}(17 \mathrm{ng} / \mathrm{min})$ at rest to $1087 \mathrm{pmol} / \mathrm{min}$ during exercise $(60 \mathrm{~W})$ in the VVI mode and $545 \mathrm{pmol} / \mathrm{min}$ in the VAT mode. Dopamine overflow fromo the heart was $<5 \mathrm{pmol} /$ at rest but increased 2-5 fold during exercise. Also arterial concentrationso

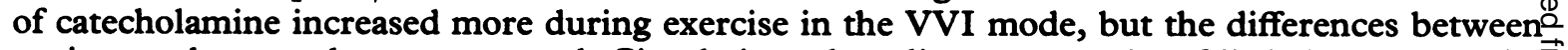
pacing modes were less pronounced. Circulating adrenaline seems to be of little importance for $\overrightarrow{\overrightarrow{\vec{B}}}$ cardiac function under these conditions; in healthy individuals the arterial concentrations of adrenaline attained in this study have small effects. Cardiac noradrenaline overflow correlated with pulmonary capillary venous pressures and atrial rates in both pacing modes, indicating a relation between cardiac sympathetic activity and cardiac function.

Enhanced cardiac release of noradrenaline may increase cardiac contractility and thereby: partially compensate for the lack of heart rate responsiveness to exercise during VVI pacing.

The beneficial haemodynamic effects of dual chamber pacing (VAT, VDD, DDD) with preserved atrioventricular synchrony and rate responsiveness compared with ventricular demand pacing (VVI) at a constant heart rate are well documented. ${ }^{1-5} \mathrm{~A}$ recent study also suggests that the prognosis of patients with atrioventricular block may be more favourable with dual chamber pacing than with VVI pacing. ${ }^{6}$ When the heart is paced at a constant rate, cardiac output

Requests for reprints to Dr Paul Hjemdahl, Department of Pharmacology, Karolinska Institutet, Box 60 400, S-104 01 Stockholm, Sweden.

Accepted for publication 23 February 1988 can only increase by a change in stroke volume, caused by increased contractility or by Starling을. mechanisms, brought about by enhanced venous return.

Sympathetic nerve activity helps to regulate heart 0 rate and contractility in the normal and failing $N$ heart. ${ }^{78}$ Circulating adrenaline may contribute to the regulation of cardiac function, since small increaseso in arterial adrenaline concentrations can elicit mainly stroke volume dependent increases of cardiac output $\stackrel{+}{+}$ in human beings.' Sympathoadrenal mechanisms have been implicated in the cardiac adaptation to exercise under different pacing conditions, ${ }^{45}$ but cardiac sympathetic nerve activity and circulating $\underset{\mathscr{Q}}{\mathscr{Q}}$ 


\section{Sympathetic activity and pacing}

concentrations of catecholamine have not, to our knowledge, been measured during exercise in individuals on different pacing modes.

Plasma concentrations of noradrenaline are considered to be a good indicator of sympathetic nerve activity $^{10}$ and several studies of plasma concentrations of noradrenaline in the peripheral venous system have been performed to assess sympathetic activity in relation to cardiac function. ${ }^{11}$ Heart failure is associated with raised concentrations of noradrenaline in venous plasma at rest and during exercise. ${ }^{12-14}$ Sympathetic nerve activity, however, is not uniformly regulated and may vary considerably between organs, and responses to various kinds of stress may also vary considerably between organs. ${ }^{15}$ The heart contributes only about $3 \%$ of the noradrenaline in arterial plasma. ${ }^{16}$ About half of the noradrenaline in antecubital venous plasma is derived from the forearm tissues and stress may influence sympathetic activity in these peripheral tissues and the heart quite differently. ${ }^{17}$ Similarly, Fischer Hansen et al estimated that approximately half of the noradrenaline measured in coronary sinus plasma was derived from the heart. ${ }^{18}$ Therefore, it seems reasonable that cardiac sympathetic nerve activity should be assessed in terms of noradrenaline overflow from the heart rather than by measurements of noradrenaline concentrations in peripheral venous plasma. ${ }^{19} 20$

The present study was undertaken to evaluate the roles of cardiac sympathetic nerve activity and circulating catecholamines in patients with complete heart block treated with dual chamber pacemakers. Catecholamine concentrations in arterial plasma and the coronary sinus overflow of noradrenaline were measured at rest and during exercise with the pacemakers programmed in the atrial synchronised mode (VAT) or the ventricular inhibited mode (VVI) (that is at a constant heart rate).

\section{Patients and methods}

\section{PATIENTS}

We studied eight patients (seven men) aged $66-80$ (mean 74) years. They had been treated with DDD pacemakers for a mean of 26 (range 2-96) months because of symptomatic high degree atrioventricular block of unknown aetiology. Two patients had clinical signs of heart failure; one of them had slight to moderate incompetence of the aortic valve. One patient had effort angina. Table 1 shows some clinical data including exercise capacities in the sitting position. Informed consent was obtained and the study was approved by the ethics committee of the Karolinska Hospital.

\section{PROCEDURE}

The patients underwent two exercise tests in the supine position. They rested for an hour between tests. The pulse generator was randomly programmed for VAT or VVI pacing about an hour before catheterisation. Four of the patients were studied in the VAT mode first. After we had completed the investigation in the first selected mode we programmed the pulse generator to the other mode.

All patients underwent cardiac catheterisation after premedication with diazepam ( $5 \mathrm{mg}$ ). A SwanGanz catheter was inserted percutaneously under local anaesthesia into an antecubital vein and positioned in the pulmonary artery under fluoroscopic guidance. A thermodilution catheter was inserted by a similar technique via the antecubital vein on the other arm and positioned in the coronary sinus. A short Teflon catheter was introduced into the right brachial artery. The catheters were connected to electromechanical transducers. The pressures were registered on a Mingograph (Sicor) and the values were processed in a computer (IBM 1800). The mid-

Table 1 Clinical data and symptom limited exercise capacity in patients in the sitting position during pretrial tests in the VVI and $V A T$ modes

\begin{tabular}{|c|c|c|c|c|c|c|c|c|}
\hline \multirow{2}{*}{$\begin{array}{l}\text { Case } \\
\text { No }\end{array}$} & \multirow[b]{2}{*}{ Age } & \multirow[b]{2}{*}{ Sex } & \multirow{2}{*}{$\begin{array}{l}B S A^{\star} \\
\left(m^{2}\right)\end{array}$} & \multirow{2}{*}{$\begin{array}{l}\text { Heart volume } \\
\left(\mathrm{ml} / \mathrm{m}^{2}\right)\end{array}$} & \multicolumn{2}{|c|}{ Exercise capacity (W) } & \multirow{2}{*}{$\begin{array}{l}\text { Other } \\
\text { relevant disease }\end{array}$} & \multirow[b]{2}{*}{ Medication } \\
\hline & & & & & $V V I$ & $V A T$ & & \\
\hline $\begin{array}{l}1 \\
2 \\
3\end{array}$ & $\begin{array}{l}77 \\
67 \\
74\end{array}$ & $\begin{array}{l}\mathbf{M} \\
\mathbf{M} \\
\mathbf{M}\end{array}$ & $\begin{array}{l}1.76 \\
1.86 \\
1.82\end{array}$ & $\begin{array}{l}500 \\
500 \\
460\end{array}$ & $\begin{array}{r}120 \\
85 \\
100\end{array}$ & $\begin{array}{r}130 \\
90 \\
120\end{array}$ & \multirow[t]{3}{*}{$\begin{array}{l}\text { Aortic incompetence } \\
\text { Congestive heart failure }\end{array}$} & $\begin{array}{l}\text { Digoxin } 0.25 \mathrm{mg} \times 1 \\
\text { Furosemide } 40 \mathrm{mg} \times 2 \\
\text { Potassium chloride }\end{array}$ \\
\hline $\begin{array}{l}4 \\
5\end{array}$ & $\begin{array}{l}76 \\
80\end{array}$ & $\begin{array}{l}\mathbf{M} \\
\mathbf{M}\end{array}$ & $\begin{array}{l}1.82 \\
1.70\end{array}$ & $\begin{array}{l}360 \\
450\end{array}$ & $\begin{array}{l}130 \\
100\end{array}$ & $\begin{array}{l}140 \\
115\end{array}$ & & \multirow{2}{*}{$\begin{array}{l}\text { Furosemide } 40 \mathrm{mg} \times 1 \\
\text { Potassium chloride } \\
\text { Digoxin } 0 \cdot 13 \mathrm{mg} \times 1 \\
\text { Furosemide } 40 \mathrm{mg} \times 1\end{array}$} \\
\hline 6 & 75 & $\mathbf{M}$ & 1.88 & 560 & 100 & 110 & & \\
\hline $\begin{array}{l}7 \\
8\end{array}$ & $\begin{array}{l}66 \\
76\end{array}$ & $\begin{array}{l}\mathbf{F} \\
\mathbf{M}\end{array}$ & $\begin{array}{l}1.64 \\
2.00\end{array}$ & $\begin{array}{l}500 \\
500\end{array}$ & $\begin{array}{l}90 \\
85\end{array}$ & $\begin{array}{l}100 \\
100\end{array}$ & Angina pectoris & $\begin{array}{l}\text { Furosemide } 40 \mathrm{mg} \times 1 \\
\text { Potassium chloride }\end{array}$ \\
\hline
\end{tabular}

^Body surface area. 
thoracic level was taken as zero reference level for pressures. Systemic vascular resistance was calculated as the mean brachial artery pressure divided by cardiac output. Cardiac output was determined by the direct Fick method. Ventilation and oxygen uptake were measured with a ventilation monitor and an argon dilution technique (Bourns Inc, Model Ls 75), which were checked regularly against a dynamic pneumotachograph calibrator. Inspired and expired air was analysed on line for oxygen, carbon dioxide, nitrogen, and argon by a mass spectrometer (20th Century Electronics, Model $200 \mathrm{Mga}$ ) calibrated with a gas mixture analysed by the Scholander technique. Oxygen consumption reached a plateau on each work load. We measured coronary blood flow by the continuous thermodilution technique after injection of an isotonic saline solution at room temperature. ${ }^{21}$ We used the mean of 2-4 measurements to calculate coronary blood flow.

Measurements were performed and blood was sampled with the patient supine at rest with both legs placed on the pedals $15 \mathrm{~cm}$ above the table and during the sixth minute of exercise at the work load $30 \mathrm{~W}$. If possible, patients completed an additional work period at $60 \mathrm{~W}$. At the end of each steady state condition, blood samples were drawn simultaneously from the coronary sinus and the brachial artery to measure plasma catecholamines. To assess coronary sinus noradrenaline overflow, we measured coronary blood flow before and after taking each blood sample.

Samples of blood $(10 \mathrm{ml})$ were collected in ice-cold centrifuge tubes containing ethylene diaminetetraacetic acid to give a final concentration of $10 \mathrm{mmol} / \mathrm{l}$. After centrifugation at $+4^{\circ} \mathrm{C}$, plasma was removed and stored at $-80^{\circ} \mathrm{C}$ until analysis. Plasma concentrations of noradrenaline, adrenaline and dopamine were measured by high performance cation exchange liquid chromatography with electrochemical detection. ${ }^{22}{ }^{23}$ The assay has a sensitivity of $<0.05 \mathrm{nmol} / 1$ and inter and intra assay coefficients of variation of 9$12 \%$ at $0 \cdot 1-0 \cdot 2 \mathrm{nmol} / 1$ (that is basal adrenaline and dopamine concentrations) and $2-3 \%$ above $1 \mathrm{nmol} / 1$ (that is basal noradrenaline concentrations) and has been validated. ${ }^{23}$ In one case adrenaline was not measured because of interference in the assay. In another case a couple of test tubes were broken during centrifugation.

Coronary plasma flow was calculated from individually determined haematocrit values. Noradrenaline overflow from the heart was calculated as the difference between plasma concentrations of noradrenaline in the coronary sinus and the arterial plasma multiplied by coronary sinus plasma flow. To correct for the removal of noradrenaline from arterial plasma by the heart, we calculated the extraction of endogenous adrenaline, which can be used to assess the extraction of noradrenaline $\mathrm{e}^{2024} 25$ and dopamine ${ }^{25}$ in an organ. Thus a "corrected" difference in the plasma concentration of noradren aline over the heart was multiplied by the coronarye sinus plasma flow. This gives a better estimate of the true organ contribution to the noradrenalines

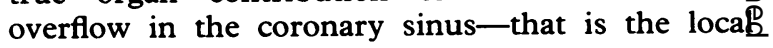
sympathetic nerve activity.

Results are presented as mean values (SEM) Statistical analyses were performed by three factor analysis of variance (ANOVA) and by linear regres $\vec{\omega}$ sion analysis by the least squares method.

\section{Results}

All eight patients completed exercise at $30 \mathrm{~W}$ bu only six patients managed to exercise for six minutes at $60 \mathrm{~W}$. The mean (SD) exercise capacities of patients in the sitting position (table 1 ) were higher during VAT pacing than during VVI pacing ( 119 (17) $v 101$ (16) W; p $<0.001$ ).

HAEMODYNAMIC VARIABLES

Figures 1 and 2 show the haemodynamic data. Witt VVI pacing the mean (SEM) ventricular heart rate did not change during exercise (70 beats/min) whereas atrial rate increased from $76(5)$ to 118 (7) beats/min. The atrial rate was lower during VA pacing $(p<0.01)$ both at rest and during exercise. increased from 65 (4) to 103 (5) beats/min at tho highest work load (fig 1). None of the patients ha@ ventriculoatrial conduction during VVI pacing Stroke volumes were 61 (3) $\mathrm{ml}$ in the VVI mode and $71(5) \mathrm{ml}$ in the VAT mode $(\mathrm{p}<0.05)$ at rest an increased by $69 \%(\mathrm{p}<0.001)$ and $23 \%$ (NS by ANOVA) respectively during exercise. The difference in stroke volume response, as shown by the interaction term of the ANOVA, was significant ( $p$ $0.001)$. The resulting values for cardiac output. tended to be lower in the VVI mode at rest and wer8 significantly lower during exercise (for example $6 \cdot \overline{7}$ $(0.2)$ v $7.3(0.3) 1 / \mathrm{min}$ at $30 \mathrm{~W}$; p < 0.01 ; fig 19 During VVI pacing cardiac output increased sig nificantly less in response to exercise $(p<0.001$ b ANOVA). Oxygen consumption was similar in the two pacing modes both at rest and during exercise (with increases from approximately 250 to $1000 \mathrm{ml}$ at standard temperature and pressure (dry) per minut in both modes). Consequently, the arteriovenoug oxygen concentration differences were significantlos (about $10-15 \%$ ) larger throughout the experimente in the VVI mode $(p<0.001$ by ANOVA; fig 1 ) Coronary blood flow increased during exercise, but these values were similar for the two pacing modes (fig 2). Systolic blood pressure was not different in the two pacing modes either at rest or during exercis 


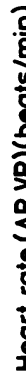

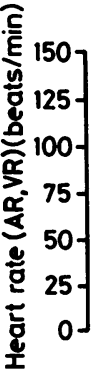

(a)

IT $p<0.001$ (VR)

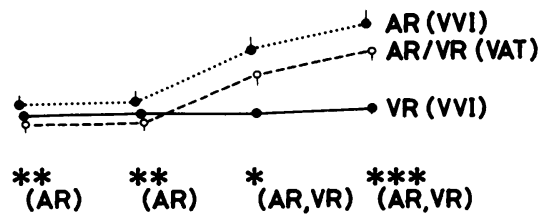

(b)

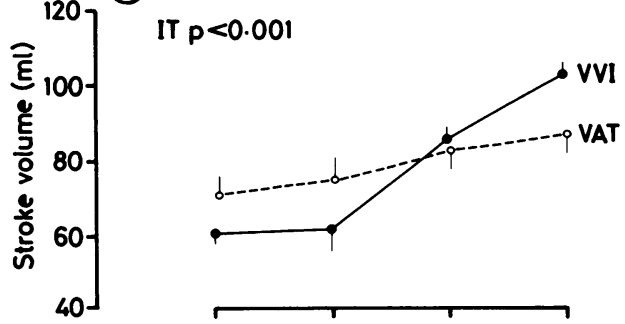

(c)

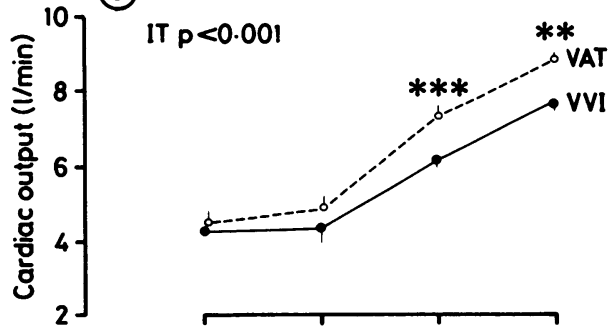

(C)

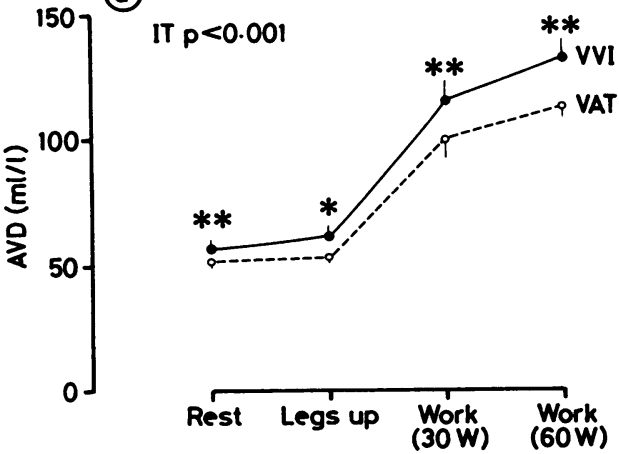

Fig 1 Mean values (SEM) for heart rate (atrial ( $A R$ ) and ventricular (VR)), stroke volume, cardiac output, and arteriovenous oxygen concentration difference ( $A V D)$ during $V V I$ or $V A T$ pacing. $A R$ and $A V D$ were significantly higher throughout the experiments during VVI pacing ( $p<0.001$ by ANOVA). The figure shows the $p$ values $(\star \star<0.01$ and $\star \star \star<0.001)$ when the two pacing conditions were compared at individual time points after the ANOVA had shown differences for the variable. Significance levels are given when the interaction term (IT) indicated that changes over time differed between pacing modes.

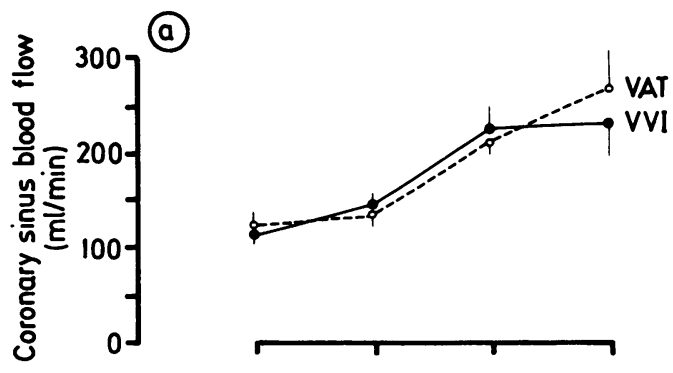

(b)

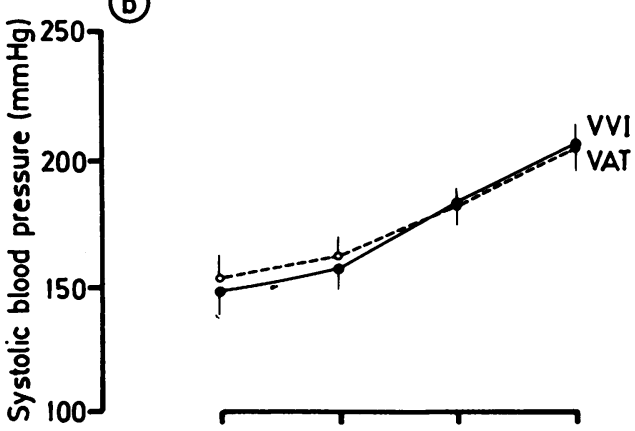

(C)

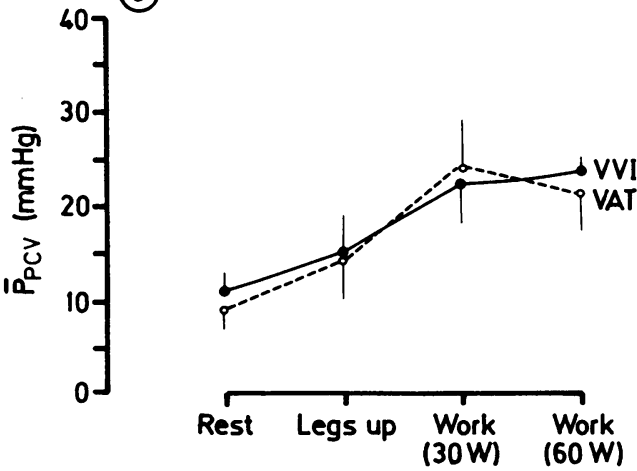

Fig 2 Coronary sinus blood flow, systolic blood pressure, and pulmonary capillary venous pressure $\left(\bar{P}_{\text {pco }}\right)$. See legend to fig 1 for symbols.

(fig 2). During exercise diastolic blood pressure increased in the VAT mode (from 75 (3) to 92 (5) $\mathrm{mm} \mathrm{Hg} ; \mathrm{p}<0.001$ ) but not in the VVI mode. These responses differed significantly $(p<0.001$ by ANOVA). Mean arterial blood pressure was similar at rest for both modes but increased more during exercise in the VAT mode (for example 127 (5) $v 119$ (6) $\mathrm{mm} \mathrm{Hg}, \mathrm{n}=8$, at $30 \mathrm{~W}$; $\mathrm{p}<0.01$ ). Systemic vascular resistance was reduced during exercise $(p<$ 0.001 ) and tended to be approximately $10-15 \%$ lower in the VAT mode, but the difference between modes was not significant.

Pulmonary arterial pressures were similar in the 
Table 2 Mean ( SEM) catecholamine concentrations in arterial $(A)$ and coronary sinus $(C S)$ plasma $(n=6-8)$, adrenaline extraction by the heart $(n=5-7)$, and corrected noradrenaline and dopamine overflow from the heart $(n=5-7)$.

\begin{tabular}{|c|c|c|c|c|c|c|c|c|c|}
\hline & \multicolumn{2}{|c|}{ Noradrenaline (nmol l) } & \multicolumn{2}{|c|}{ Adrenaline (nmol/l) } & \multicolumn{2}{|c|}{ Dopamine (nmol l) } & \multirow{2}{*}{$\begin{array}{l}\text { Adrenaline } \\
\text { extraction } \\
\left({ }^{\circ}, 1\right)\end{array}$} & \multirow{2}{*}{$\begin{array}{l}\text { Nor- } \\
\text { adrenaline } \\
\text { overflow } \\
\text { (pmolimin) }\end{array}$} & \multirow{2}{*}{$\begin{array}{l}\text { Dopamine } \\
\text { overflow } \\
\text { (pmol min) }\end{array}$} \\
\hline & CS & $A$ & $C S$ & $A$ & $C S$ & $A$ & & & \\
\hline \multicolumn{10}{|l|}{ Resting: } \\
\hline VVI & $3.93(0.81)$ & $2.64(0.50)$ & $0.17(0.04)$ & $0.25(0.07)$ & $0 \cdot 16(0.02)$ & $0.13(0.02)$ & $29(4)$ & $141(46)$ & $3 \cdot 4(1 \cdot 7)$ \\
\hline VAT & $3.14(0.66)^{\star}$ & $2 \cdot 18(0.41)$ & $0.14(0.04)$ & $0.20(0.07)^{\star}$ & $0.12(0.02)^{\star}$ & $0.14(0.04)$ & $22(8)$ & $109(45)$ & $2 \cdot 8(1.7)$ \\
\hline \multicolumn{10}{|l|}{ Legs up: } \\
\hline VVI & $3.08(0.36)$ & $2.62(0.59)$ & $0.18(0.03)$ & $0.28(0.06)$ & $0.15(0.02)$ & $0.13(0.03)$ & $31(6)$ & $112(30)$ & $4 \cdot 6(1.5)$ \\
\hline VAI & $2.50(0.34)^{\star}$ & $1.99(0.29)$ & $0 \cdot 17(0 \cdot 04)$ & $0.23(0 \cdot 06)^{\star}$ & $0 \cdot 10(0 \cdot 01)^{\star \star \star}$ & $0.11(0.02)$ & $25(4)$ & $82(24)$ & $-0.2(1.6)$ \\
\hline \multicolumn{10}{|l|}{ Work (30 W): } \\
\hline VVI & $14.82(5 \cdot 25)$ & $5.75(0.54)$ & $0.35(0.10)$ & $0.42(0.08)$ & $0.35(0.12)$ & $0.20(0.03)$ & $18(9)$ & $565(79)$ & $4 \cdot 7(3 \cdot 2)$ \\
\hline $\begin{array}{l}\text { VAT } \\
\text { Work }(60 \mathrm{~W})\end{array}$ & $8.87(2.94)^{\star \star}$ & $3.83(0.43)^{\star}$ & $0.27(0.05)$ & $0.30(0.07)$ & $0.21(0.06)^{\star \star}$ & $0.13(0.02)$ & $0(8)$ & $271(131)^{\star}$ & \\
\hline \multicolumn{10}{|l|}{ Work $(60 \mathrm{~W})$ : } \\
\hline $\begin{array}{l}\text { VVI } \\
\text { VAI }\end{array}$ & $18.35(2.5)$ & $9.80(1.56)$ & $0.61(0.19)$ & $0.71(0.16)$ & $0.44(0.07)$ & $0.29(0.04)$ & $6(5)$ & $1087(265)$ & $23.9(7.9)$ \\
\hline $\begin{array}{l}\text { VAT } \\
\text { Differences }\end{array}$ & $11 \cdot 07(1 \cdot 80)^{\star \star}$ & $7 \cdot 49(1 \cdot 46)$ & $0.49(0 \cdot 12)$ & $0.56(0.11)$ & $0.24(0.04)^{\star}$ & $0 \cdot 17(0 \cdot 02)$ & $12(11)$ & & \\
\hline \multicolumn{10}{|c|}{$\begin{array}{l}\text { Differences } \\
\text { between VVI } \\
\text { and VAT in } 3 \\
\text { fact }\end{array}$} \\
\hline $\begin{array}{l}\text { Significance } \\
\text { of I'T in }\end{array}$ & & & & & & & & & \\
\hline $\begin{array}{l}3 \text { factor } \\
\text { ANOVA }\end{array}$ & $\mathrm{p}<0.001$ & & & & $p<0.01$ & $\mathrm{p}<0.05$ & & $\mathrm{p}<0.01$ & \\
\hline
\end{tabular}

Two patients could not exercise at a work load of $60 \mathrm{~W}$. In one patient adrenaline concentrations could not be analysed because of interference. ${ }^{\star} \mathrm{p}<0.05$, $\star \star p<0.01, \star \star \star p<0.001$ for 2 factor analyses (VVI 2 . VAT) performed at different time points after the 3 factor ANOVA had shown significant differences. A significant interaction term (IT) indicates differences between VVI and VAT modes (that is a difference in the slope of the curve) in the change of a variable over time. Significant effects over time (that is an effect of work) were seen for all variables.

two pacing modes (for example $25(3): 12(3) \mathrm{mm} \mathrm{Hg}$ at rest and $49(6) / 25(5) \mathrm{mm} \mathrm{Hg}$ at $30 \mathrm{~W}$ in the VAT mode). Right atrial mean pressure increased two to three fold from 5 (1) $\mathrm{mm} \mathrm{Hg}$ in both pacing modes and tended to be higher $(\mathrm{p}<0 \cdot 1$ by ANOVA) during VVI pacing. Pulmonary capillary venous pressures varied considerably between patients, but values were similar within patients in the two pacing modes both at rest and during exercise (fig 2).

\section{CATECHOLAMINES}

Concentrations of noradrenaline, adrenaline, and dopamine in arterial plasma at rest and during exercise were higher in the VVI mode (table 2). Increases in arterial plasma noradrenaline induced by exercise were considerably larger than those in adrenaline and dopamine, but analysis of variance showed that these increases were not significantly different. At rest the heart extracted approximately $25-30^{\circ}$ " of circulating adrenaline in both pacing modes (table 2). During exercise the cardiac extraction of adrenaline fell to about $10^{\circ}{ }^{\circ}$ (NS). Plasma concentrations of noradrenaline in the coronary sinus were higher than the arterial concentrations both at rest and during exercise. There were large interindividual variations in coronary sinus noradrenaline concentrations during exercise (for example 3.33$50.0 \mathrm{nmol} / 1$ at $30 \mathrm{~W}$ in the VVI mode). Concentrations of noradrenaline in the coronary sinus were, however, consistently higher during VVI than dur- ing VAT pacing (table 2). Also plasma dopamine concentrations in the coronary sinus were higher than the arterial concentrations and increased significantly ( $p<0.01)$ during exercise (table 2). They were higher during VVI pacing both at rest and during exercise $(p<0.01 ;$ table 2$)$ and they increased more in the VVI mode (table 2).

Coronary sinus noradrenaline overflow tended to be greater at rest and was twice as large in the VVI mode as in the VAT mode during exercise (table 2, fig 3). Cardiac noradrenaline overflow responses to exercise were significantly enhanced during VVI pacing ( $p<0.01$ by ANOVA). Dopamine overflow was less than $5^{\circ}$ " of the noradrenaline overflow into the coronary sinus both at rest and during exercise and in both pacing modes. Dopamine overflow from the heart did increase $(p<0.01)$ during exercise and again the response during VVI pacing tended to be larger than that seen during VAT pacing (table 2, fig 3). The difference in dopamine overflow was, however, not significant. In the calculations of noradrenaline and dopamine overflow shown in table 2 , the removal of catecholamines from arterial plasma by the heart was assessed by the cardiac extraction of adrenaline, in order to obtain a more accurate measure of the cardiac contribution to noradrenaline and dopamine in the coronary effluent (see methods). In a few instances concentrations of adrenaline in the coronary sinus were slightly higher than in the arterial concentrations. Catecholamine extraction by 
Sympathetic activity and pacing

(a)
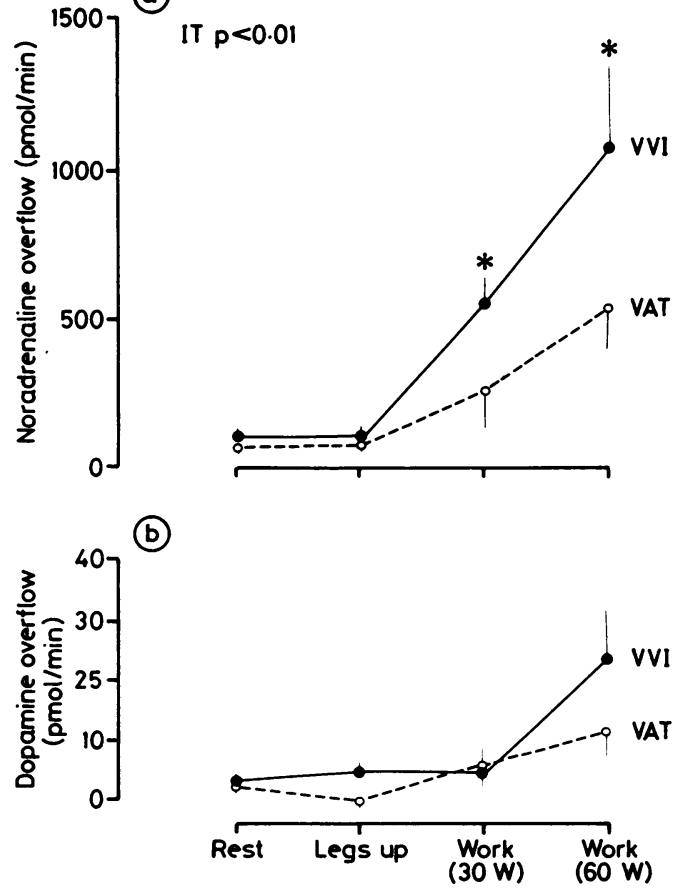

Fig 3 Noradrenaline and dopamine overflow into coronary sinus plasma. Catecholamine overflow values were corrected (according to adrenaline extraction) for the removal of catecholamines from arterial plasma by the heart. Only paired observations (where results were obtained from each patient under both pacing conditions) are given. See table 2 and results for three factor $A N O V A$ analyses. ( ${ }^{\star} p<0.05$ for differences between $V V I$ and $V A T$ ). the heart was then considered to be $0 \%$. Results and conclusions about noradrenaline overflow were, however, similar even if adrenaline extraction was said to be $<0 \%$ (in fact the difference between pacing modes became slightly larger) or if cardiac catecholamine extraction was not taken into account at all. VVI pacing was clearly associated with enhanced noradrenaline overflow into the coronary sinus.

\section{CORRELATIONS}

Plasma concentrations of noradrenaline in the coronary sinus were significantly correlated with atrial rate (fig 4), as were cardiac noradrenaline overflow values during VVI $(r=0.78, p<0.001)$ and during VAT $(r$ $=0.69, \mathrm{p}<0.001)$ pacing. Pulmonary capillary venous pressures were correlated with noradrenaline concentrations in coronary sinus plasma and noradrenaline overflow from the heart both at rest and during exercise. Pooling of VVI and VAT pacing values, because the study group was so small, gave the following correlation coefficients: pulmonary capillary venous pressure $v$ noradrenaline concentrations at rest $(r=0.51, n=16, p<0.05)$, noradrenaline overflow at rest $(r=0.79, n=13, p<$ $0.01)$, noradrenaline concentrations at $30 \mathrm{~W}(\mathrm{r}=$ $0.75, \mathrm{n}=14, \mathrm{p}<0.01$ ), and noradrenaline overflow at $30 \mathrm{~W}(r=0.65, \mathrm{n}=11, \mathrm{p}<0.05)$. These correlations were generally stronger in the VVI mode than in the VAT mode, but the numbers were too small for valid analysis.

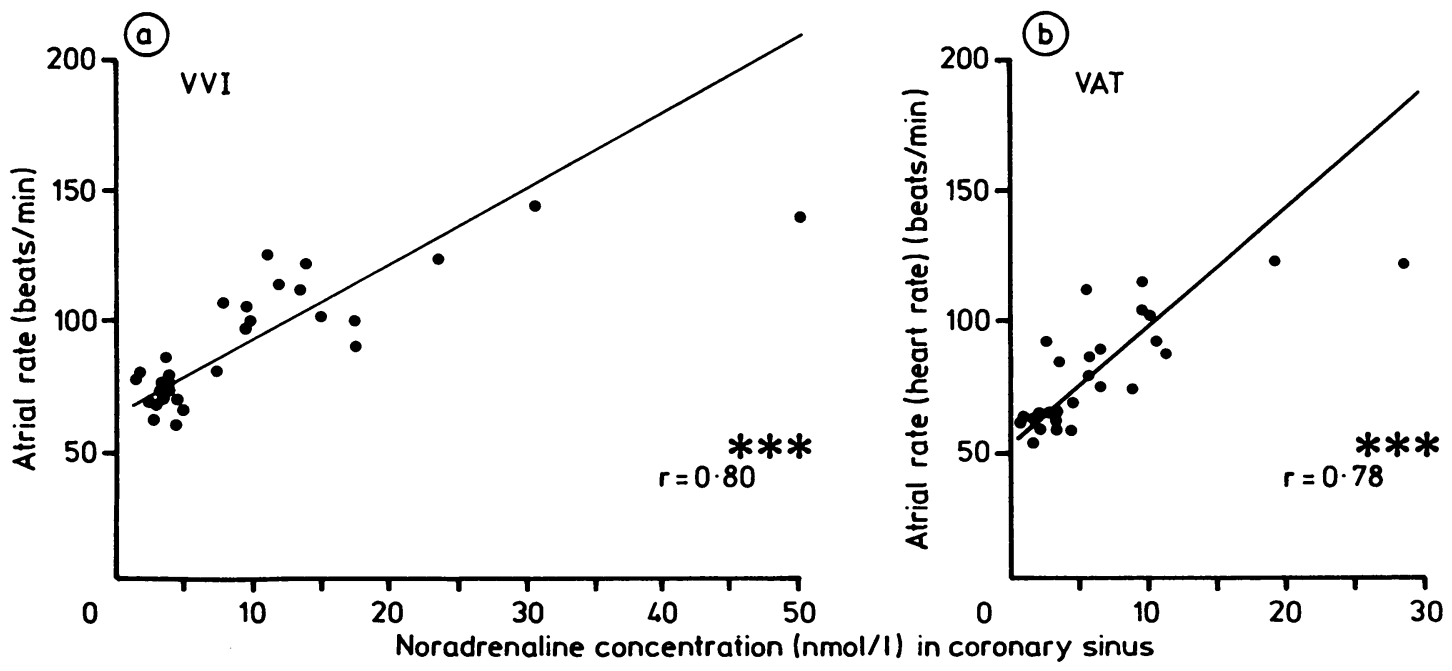

Fig 4 Correlations between noradrenaline concentrations in coronary sinus plasma and atrial rate during VVI pacing (a) and heart rate during $V A T$ pacing (b). Similar relations were found between these variables and cardiac noradrenaline overflow values (see text). ${ }^{\star \star \star} p<0.001$. 


\section{Discussion}

The present investigation confirms previous observations $^{1-5}$ that cardiac output is improved during exercise when VAT pacing allows heart rate to increase in response to the sinus node activity. The lack of ventricular rate responsiveness during VVI pacing is partially compensated for by an increased stroke volume response to exercise. The proposed explanation for the high atrial rate seen during exercise with VVI, as compared with VAT pacing (references 3 and 4 and present results) is an increase in sympathetic nerve activity. Indeed, an enhanced cardiac sympathetic response to exercise in the VVI mode would be a most appropriate way to increase contractility when demands on increased stroke volume are high. ${ }^{6}$ The present data clearly demonstrate that cardiac sympathetic nerve activity is enhanced during VVI pacing, especially when demands are increased by exercise. Thus coronary sinus noradrenaline concentrations and cardiac noradrenaline overflow values were higher in this pacing mode. It is noteworthy that the enhancement of sympathetic activity seen during VVI, as compared with VAT pacing, was greater in the heart than in the rest of the body. So cardiac noradrenaline overflow increased more markedly than arterial noradrenaline concentrations (by $404 v 119 \%$ at $30 \mathrm{~W}$ ) during exercise in the VVI mode. Similarly, the enhanced atrial rate response to exercise was not accompanied by enhanced blood pressure or oxygen consumption in response to exercise during VVI, as compared with VAT pacing. Cardiac sympathetic nerve activity seems to be more closely related to cardiac demands than to sympathetic nerve activity in the rest of the body.

How well does coronary sinus noradrenaline overflow reflect cardiac sympathetic nerve activity? Animal studies have shown a frequency dependent overflow of noradrenaline from the heart during stimulation of the sympathetic cardiac nerves, ${ }^{26-28}$ and correlations between increases in myocardial contractility and noradrenaline overflow. ${ }^{26} 28$ Coronary vasodilatation or mechanical factors associated with myocardial contractions or both may facilitate noradrenaline diffusion into coronary sinus plasma, as has been shown in high frequency pacing. ${ }^{29}$ It is, however, unlikely that such a difference in noradrenaline diffusion could explain our pacing results because noradrenaline overflow was highest during fixed rate pacing. Furthermore, blood flow in the coronary sinus was similar in the two pacing modes both at rest and during exercise. Though direct techniques cannot be used in patients to verify that coronary sinus noradrenaline overflow mirrors cardiac sympathetic nerve activity in humans, the
Pehrsson, Hjemdahl, Nordlander, Aström $\stackrel{\frac{1}{\mathbb{D}}}{\frac{D}{7}}$ present findings of clear-cut correlations between $c$. atrial rates and cardiac noradrenaline overflow in $\Rightarrow$ both pacing modes support the contention that $\frac{\text { ? }}{?}$ coronary sinus noradrenaline overflow does reflect? cardiac sympathetic nerve activity.

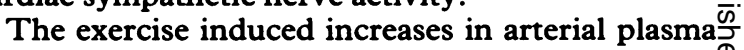
adrenaline concentrations were considerably smallero than the increases in cardiac noradrenaline overflow. Cardiac sympathetic nerve activity was probably the $-\vec{\circ}$ dominating sympathoadrenal factor influencingcardiac function in the present study, because $\vec{\omega}$ neurogenic mechanisms usually are more important ${ }^{\circ}$ than circulating catecholamines in the control of heart function ${ }^{78} 15$ and the arterial adrenaline concen- 8 trations attained in the present study were low. For $\omega$ example, an increase in arterial plasma adrenaline ${ }_{-}^{N}$ concentrations to $1.3 \mathrm{nmol} / 1$ by intravenous infusion ${ }^{N}$ increased the heart rate by only 5 beats $/ \mathrm{min}$ and 3 stroke volume by $10 \%$ in healthy volunteers. ${ }^{8}$ The only patient in the present study with adrenaline $\left(\frac{D}{8}\right.$ concentrations $>1.3 \mathrm{nmol} / 1$ during exercise had $\mathrm{a}_{\mathbb{\Phi}}$ simultaneously determined coronary sinus 3 noradrenaline overflow of $2026 \mathrm{pmol} / \mathrm{min}$ - that is $\mathbb{1}$ the highest value recorded. Thus it is reasonable to assume that circulating adrenaline was of littleo importance in the cardiac adaptation to exercise in the different pacing modes.

Adjustments of the peripheral circulation to exercise are important to cardiac function, becauseō afterload and venous return are important determinants of stroke volume. ${ }^{7}$ For example during low level $\stackrel{1}{\circ}$ exercise Frank-Starling mechanisms increased $\vec{\circ}$ stroke volume in denervated hearts of heart trans- 3 plant recipients. ${ }^{30}$ In the present study the increase in arterial concentrations of noradrenaline induced by exercise tended to be higher during VVI pacing. This might reflect increased activity of peripheralo vasoconstrictor nerves and may be associated with? venoconstriction and enhanced venous return. Even 3 . though right atrial mean pressures tended to bei higher in the VVI mode during exercise, we cannot 3 tell from the present data whether this contributed to ${ }_{\circ}$ the enhanced response of stroke volume to exercise during VVI pacing because ventricular volumes wereo not monitored.

We have, so far, no reference material comprised of $N$ healthy individuals. The patients in the present study were old and had impaired cardiac function, asN indicated by low cardiac output values and high ${ }_{\sigma}^{\omega}$ wedge pressures during supine exercise. Previous studies have shown that heart failure is associated with high concentrations of venous noradrenaline in $\mathbb{D}_{+}$ the forearm at rest ${ }^{11214}$ and inappropriately large $e_{p}^{+}$ increases in venous plasma noradrenaline concentra-o tions in response to exercise.$^{13}$ For reasons mentioned $\mathbb{\Phi}$ in the Introduction, these changes in noradrenaline $\mathbb{D}$ 
concentrations should be regarded as indirect measures of cardiac function (that is compensatory changes in the activity of peripheral vasoconstrictor nerves) rather than measures of cardiac sympathetic nerve activity. Cardiac noradrenaline overflow in heart failure is increased at rest. ${ }^{19}$ The cardiac noradrenaline overflow values found in the present study (approximately $100 \mathrm{pmol} / \mathrm{min}$ or $17 \mathrm{ng} / \mathrm{min}$ at rest) were in between the values reported for healthy control and patients with heart failure at rest (that is, 5 and $32 \mathrm{ng} / \mathrm{min}$, respectively) in the radiotracer infusion study of Hasking et al. ${ }^{19}$ Interestingly, we saw significant correlations between pulmonary capillary venous pressures and coronary sinus concentrations of plasma noradrenaline or cardiac noradrenaline overflow both at rest and during exercise. Thus our data support the ideas that demands influence cardiac sympathetic nerve activity and that cardiac, as well as peripheral sympathetic nerve activity is enhanced when cardiac function is compromised. In fact, the results of Hasking $e t a l^{19}$ and those of the present study indicate that the increase in compensatory sympathetic nerve activity is largest in the target organ, which emphasises the importance of regional studies of noradrenaline overflow in pathophysiological and physiological studies.

Dopamine overflow from the heart was very small in relation to noradrenaline overflow. Pharmacological doses of exogenous dopamine have wellknown cardiostimulatory effects ${ }^{31}$ and failing human hearts contain relatively high concentrations of dopamine. ${ }^{32}$ It has been suggested that dopamine is immediately conjugated to sulphate upon release in the tissues and that concentrations of conjugated dopamine would reflect dopamine release better than free dopamine concentrations in plasma. ${ }^{33}$ This is, however, not the case in the canine kidney after sympathetic nerve stimulation. ${ }^{34}$ Furthermore, renal extractions of noradrenaline and dopamine from plasma are equally large $e^{25}$ and the renal venous overflow of dopamine is even larger in relation to noradrenaline overflow than would be expected on the basis of the tissue contents of noradrenaline and dopamine. ${ }^{34}$ Thus free dopamine overflow from a tissue, as assessed in the present study, should reflect release of dopamine in the tissue. In our experience dopamine overflow is proportionally greater into renal venous plasma in the $\operatorname{dog}{ }^{34}$ and in human beings. ${ }^{35}$ The present results therefore indicate that dopamine release is very small in relation to noradrenaline release and probably only represents release of precursor dopamine stored in noradrenergic nerves in the human heart. It is doubtful whether this dopamine is physiologically important.

It has been proposed that increased cardiac turnover of catecholamines would accelerate the disease process in heart failure by reducing cardiac $\beta$ adrenoceptor sensitivity. ${ }^{36}$ Increased sympathetic nerve activity would also be expected to increase myocardial oxygen requirements and cardiac work, ${ }^{67}$ which eventually might lead to deterioration of already compromised hearts. The present findings of enhanced sympathetic responses to exercise and correlations between cardiac noradrenaline overflow and function are of particular interest in view of the indications ${ }^{6}$ that the prognosis is less good in patients with congestive heart failure on VVI pacing than on VAT pacing.

The finding that impaired adaptation to exercise during VVI pacing was accompanied by enhanced noradrenaline overflow indicates that VVI pacing at a constant heart rate is associated with enhanced activity of the cardiac sympathetic system. Dopamine release in the heart and circulating adrenaline seem to be less important than cardiac sympathetic nerve activity for the adaptation to exercise under the reported conditions. The enhanced cardiac sympathetic nerve activity during constant rate (VVI) pacing may well have adverse effects on failing or ischaemic hearts and may influence the clinical course of such patients.

The present study was supported by grants from the Swedish Heart Lung Foundation, the Swedish Medical Research Council and the Swedish Society of Medicine. We thank Ingrid Andersson, Monika Borggren, Lisbet Broman, Margareta Broman, and Maud Daleskog for technical assistance.

\section{References}

1 Samet P, Castillo C, Bernstein WH. Hemodynamic sequelae of atrial ventricular and sequential atrioventricular pacing in cardiac patients. Am Heart $J$ 1966;71:725-9.

2 Karlöf I. Haemodynamic effect of atrial triggered versus fixed rate pacing, at rest and during exercise, in complete heart block. Acta Med Scand 1975;197: 195-206.

3 Kruse I, Arnman K, Conradson T-B, Rydèn L. A comparison of the acute and long-term effects of ventricular inhibited and atrial synchronous ventricular inhibited pacing. Circulation 1982;65:846-55.

4 Pehrsson SK, Åström H. Left ventricular function after long-term treatment with ventricular inhibited compared to atrial triggered ventricular pacing. Acta Med Scand 1983;214:295-304.

5 Pehrsson SK, Åström H, Bone D. Left ventricular volumes with ventricular inhibited and atrial triggered ventricular pacing. Acta Med Scand 1983; 214:305-10.

6 Alpert MA, Curtis JJ, Sanfelippo JF, et al. Comparative 
survival after permanent ventricular and dual chamber pacing for patients with chronic high degree atrioventricular block with and without pre-existent congestive heart failure. J Am Coll Cardiol 1986; 7:925-32.

7 Braunwald E, Ross JJ Jr. Control of cardiac performance. In: Berne RM, ed. Handbook of physiologythe cardiovascular system. Sect 2, Vol I. Bethesda: American Physiological Society, 1979:533-80.

8 Levy MN, Martin PJ. Neural control of the heart. In: Berne RM, ed. Handbook of physiology-the cardiovascular system. Sect 2, Vol I. Bethesda: American Physiological Society, 1979:581-620.

9 Freyschuss U, Hjemdahl P, Juhlin-Dannfelt A, Linde B. Cardiovascular and metabolic responses to low dose adrenaline infusion-an invasive study in humans. Clin Sci 1986;70:199-206.

10 Cryer PE. Physiology and pathophysiology of the human sympathoadrenal neuroendocrine system. $N$ Engl J Med 1980;303:436-44.

11 Goldstein DS. Plasma norepinephrine as an indicator of sympathetic neural activity in clinical cardiology. $\mathrm{Am}$ J Cardiol 1981;48:1147-54.

12 Thomas JA, Marks BH. Plasma norepinephrine in congestive heart failure. Am J Cardiol 1978;41: 233-43.

13 Francis GS, Goldsmith SR, Ziesche SM, Cohn JN. Response of plasma norepinephrine and epinephrine to dynamic exercise in patients with congestive heart failure. Am J Cardiol 1982;49:1152-6.

14 Cohn JN, Levine TB, Olivari MT, et al. Plasma norepinephrine as a guide to prognosis in patients with chronic congestive heart failure. $N$ Engl $J$ Med 1984;311:819-23.

15 Folkow B, BiBona GF, Hjemdahl P, Thorén P, Wallin BG. Measurements of plasma norepinephrine concentrations in human primary hypertension. A word of caution on their applicability for assessing neurogenic contributions. Hypertension 1983;5: 399-403.

16 Esler M, Jennings G, Leonard P, Sacharias N, Burke F, Johns J, Blombery P. Contribution of individual organs to total noradrenaline release in humans. Acta Physiol Scand 1984;suppl 527:11-16.

17 Hjemdahl P, Freyschuss U, Juhlin-Dannfelt A, Linde B. Differentiated sympathetic activation during mental stress evoked by the Stroop test. Acta Physiol Scand 1984;00(suppl 527):25-9.

18 Fischer-Hansen J, Christensen NJ, Hesse B. Determinants of coronary sinus noradrenaline in patients with ischaemic heart disease: coronary sinus catecholamine concentration in relation to arterial catecholamine concentration, pulmonary artery oxygen saturation and left ventricular end-diastolic pressure. Cardiovasc Res 1978;12:415-21.

19 Hasking GJ, Esler M, Jennings GL, Burton D, Korner PI. Norepinephrine spillover to plasma in patients with heart failure: evidence of increased overall and cardiorenal sympathetic activity. Circulation 1986; 73:615-21.

20 Hjemdahl P. Plasma catecholamine determinations: analytical problems and interpretations. In: Christensen NJ, Henriksen O, Lassen NA, eds. The sympathoadrenal system. Copenhagen: Munksgaard; New
York: Raven Press, 1986:17-32.

21 Ganz W, Tamura $K$, Marcus HS, Donoso $\mathbf{R}_{\mathbf{3}}$

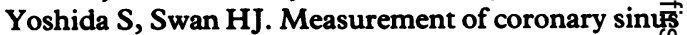
blood flow by continuous thermodilution in man. Circulation 1971;44:181-95.

22 Hjemdahl P, Daleskog M, Kahan T. Determination plasma catecholamines by high performance liquig chromatography with electrochemical detectios comparison with a radioenzymatic method. Life Sai 1979;25:131-8.

23 Hjemdahl P. Catecholamine measurements in plasm $\vec{Q}$ by high performance liquid chromatography with electrochemical detection. Methods in Enzymologes 1987;142:521-34.

24 Halter JB, Kelley KO, Gould KL. Cardiac uptake and secretion of catecholamines during adrenerg: stimulation in vivo. Am J Physiol 1982;243:E52-8.

25 Bradley $\mathrm{T}, \mathrm{Hjemdahl} P$. Renal extraction of endogenoui and radiolabelled catecholamines in the dog. Acto Physiol Scand 1986;126:505-10.

26 Levy MN, Blattberg B. Correlation of the mechanical response of the heart with the norepinephrirre overflow during cardiac sympathetic neural stimuls tion in the dog. Cardiovasc Res 1975;11:481-8.

27 Yamaguchi N, de Champlain J, Nadeau R. Correlation between the response of the heart to sympathetise stimulation and the release of endogenous catecholamines into the coronary sinus of the dog. $\mathrm{Ci}_{80}$ Res 1975;36:662-8.

28 Blombery PA, Heinzow BGJ. Cardiac and pulmonaty norepinephrine release and removal in the dog. $C_{i}$ Res 1983:53:688-94.

29 Masuda Y, Levy MN. Heart rate modulates the disposi tion of neurally released norepinephrine in cardif tissues. Cir Res 1985;57:19-27.

30 Pope SE, Stinson EB, Daughters GT, Schroeder J Ingels NB, Alderman EL. Exercise response of the denervated heart in long-term cardiac transplap recipients. Am J Cardiol 1980;46:213-8.

31 Goldberg LI. Cardiovascular and renal actions of dopamine: potential clinical applications. Pharmacol Rev 1972;24:1-29.

32 Pierpont GL, Francis GS, DeMaster EG, Levine TB, Bolman RM, Cohn JN. Elevated left ventriculä myocardial dopamine in preterminal idiopathig dilated cardiomyopathy. Am J Cardiol 1983;52: 1033-5.

33 Snider SR, Kuchel O. Dopamine: an important neur $\frac{\mathrm{O}}{\Theta}$ hormone of the sympatho-adrenal system. Sifz nificance of increased peripheral domapine release fe्ष. the human stress response and hypertension. Endoro Rev 1983;4:291-309.

34 Bradley T, Hjemdahl P. Further studies on renal ner stimulation induced release of noradrenaline and dopamine from the canine kidney in situ. Acta Physiol Scand 1984;122:369-79.

35 Hjemdahl P, Tidgren B. Differential reflex activation of noradrenaline and dopamine overflow from the human kidney [Abstract]. J Physiol (Lond) 1987;390:106P.

36 Bristow MR, Ginsburg R, Minobe W, et al. Decreasefd catecholamine sensitivity and $\beta$-adrenergic-receptor density in failing human hearts. $N$ Engl $J$ Mgd 1982;307:205-11. 